BERNIERI, João Luis; KRAEMER BORTOLOTI, José Carlos. A dificuldade de superação do individualismo no estado democrático de direito no Brasil. Revista Eletrônica Direito e Política, Programa de Pós-Graduação Stricto Sensu em Ciência Jurídica da UNIVALI, Itajaí, v.16, n.2, $2^{\circ}$ quadrimestre de 2021. Disponível em: www.univali.br/direitoepolitica - ISSN 1980-7791.

\title{
A DIFICULDADE DE SUPERAÇÃO DO INDIVIDUALISMO NO ESTADO DEMOCRÁTICO DE DIREITO NO BRASIL
}

\author{
THE DIFFICULTY OF OVERCOMING INDIVIDUALISM IN THE DEMOCRATIC RULE \\ OF LAW IN BRAZIL
}

João Luis Bernieri

José Carlos Kraemer Bortoloti²

\section{RESUMO}

O Estado Democrático de Direito no Brasil veio sob os auspícios da Constituição da República Federativa do Brasil de 1988, onde as forças se destinam assegurar os direitos sociais e individuais, a liberdade, segurança, bem-estar, o desenvolvimento, a igualdade e a justiça, tudo como valor supremo de uma sociedade fraterna. O presente trabalho articula debate com a dificuldade de superação do individualismo herdado pelo Estado de Direito liberal "pré 1988" e a possibilidade de emergência do princípio democrático "pós 1988" a partir da superação do individualismo, reconhecendo e efetivando os cidadãos em suas respectivas titularidades de direitos, consequentemente com o florescimento de oportunidades reais na vida das pessoas. Nesse entendimento, devendo existir um resgate do Estado Social no Brasil. O método de abordagem é o dialético, com a utilização de referências bibliográficas. Os elementos conclusivos indicam um modelo temporal permeado entre o Estado pré e o pós 1988, o qual acaba por criar um paradoxo deficitário para a vivência do Estado Democrático de Direito no Brasil, dando as características de que o novo continua forçosamente a utilizar as armaduras do velho.

PALAVRAS-CHAVE: Estado Social, Estado Democrático de Direito, Individualismo, Reconhecimento.

\footnotetext{
1 Bacharel em Direito (IMED/RS); Advogado no Rio Grande do Sul; membro Centro Brasileiro de Pesquisas sobre a Teoria da Justiça de Amartya Sen (CEPAS) vinculado ao Programa de Pósgraduação Scrito Sensu em Direito da Faculdade IMED, Passo Fundo, RS.

2 Pós-doutor em Direito (IMED/RS); Doutor em Direito (UNESA/RJ), com período de Doutorado Sanduíche na Faculdade de Direito da Universidade de Lisboa, Portugal, financiado pelo PDSE/CAPES; Mestre em Direito (ULBRA/RS); Professor do Curso de Direito da Faculdade IMED, Passo Fundo, RS; membro do Centro Brasileiro de Pesquisas sobre a Teoria da Justiça de Amartya Sen (CEPAS) e do Grupo de Pesquisa Direitos Culturais e Pluralismo Jurídico, ambos vinculados ao Programa de Pós-graduação Scrito Sensu em Direito da Faculdade IMED, Passo Fundo, RS. E-mail: jose.bortoloti@imed.edu.br.
} 
BERNIERI, João Luis; KRAEMER BORTOLOTI, José Carlos. A dificuldade de superação do individualismo no estado democrático de direito no Brasil. Revista Eletrônica Direito e Política, Programa de Pós-Graduação Stricto Sensu em Ciência Jurídica da UNIVALI, Itajaí, v.16, n.2, $2^{\circ}$ quadrimestre de 2021. Disponível em: www.univali.br/direitoepolitica - ISSN 1980-7791.

\section{ABSTRACT}

The Democratic Rule of Law in Brazil came under the auspices of the 1988 Constitution of the Federative Republic of Brazil, where forces are intended to ensure social and individual rights, freedom, security, well-being, development, equality and justice, all as the supreme value of a fraternal society. The present work articulates a debate with the difficulty of overcoming individualism inherited by the liberal "rule of law before-1988 and the possibility of emergence of the democratic principle post-1988 from the overcoming of individualism, recognizing and making citizens in their respective rights, consequently with the flourishing of real opportunities in people's lives. In this understanding, there must be a rescue of the welfare state in Brazil. The approach method is dialectical, with the use of bibliographic references. The conclusive elements indicate a temporal model permeated between the before and post-1988 state, which ends up creating a deficit paradox for the experience of the Democratic Rule of Law in Brazil, giving the characteristics that the new forcefully continues to use the armor of the old.

KEYWORDS: Social State, Democratic Rule of Law, Individualism, Recognition.

\section{INTRODUÇÃO}

O Estado Democrático de Direito brasileiro, por meio da Constituição Federal de 1988, trouxe a perspectiva transformadora democrática, levando a superar os modelos autoritários que o sucederam. Confere ao povo brasileiro a esperança que em outros tempos foi levantada pela classe burguesa, comprometendo-se em assegurar a todos os indivíduos igualdade de condições, erradicar as diferenças de classes e descentralização do poder para que esse passasse a ser originariamente do povo.

Acolhendo como princípios basilares do Estado brasileiro, a cidadania e a dignidade da pessoa humana figuram como guias da atuação estatal. Contudo, passados trinta e três anos do advento da democracia no Brasil, ainda se amarga a dificuldade de se tornar uma sociedade altruísta, experimentando as mazelas de uma sociedade egocêntrica, centrada em obter suas conquistas individuais.

Partindo do método dedutivo, engendrado a partir da consulta literária, dados e outras referências, o presente texto busca provocar a percepção sobre a dificuldade de promoção de direitos que transcendem o indivíduo e que, em 
BERNIERI, João Luis; KRAEMER BORTOLOTI, José Carlos. A dificuldade de superação do individualismo no estado democrático de direito no Brasil. Revista Eletrônica Direito e Política, Programa de Pós-Graduação Stricto Sensu em Ciência Jurídica da UNIVALI, Itajaí, v.16, n.2, $2^{\circ}$ quadrimestre de 2021. Disponível em: www.univali.br/direitoepolitica - ISSN 1980-7791.

consequência, terminam por restringir também o acesso a considerável gama de cidadãos que não possuem condições, tanto de percepção sobre seus direitos, assim como fadados ao esquecimento da sociedade, a qual briga com sua feição fraterna.

Para isso, as provocações dialogam com a Teoria do Reconhecimento de Axel Honneth e as capabilities de Amartya Sen, como pontos opostos da visão individualista-excentrista, bem como perspectiva para a saída da sociedade brasileira da visão pura e excêntrica de seus direitos individuais-patrimoniais.

À guisa das considerações encontradas pelo trabalho, é possível afirmar que o ser em reconhecimento, o indivíduo inserido em uma conjuntura de compreensão, respeito e interação com direitos que transcendem ao indivíduo, fomenta capabilities e forma um ciclo de efetivação de direitos, bem como sua interação com a atuação frente ao Estado passa de espectador para interlocutor no Estado Democrático de Direito.

\section{UM RESGATE DA MEMÓRIA SOBRE O ESTADO SOCIAL}

Com o crescimento acelerado e o desenvolvimento descontrolado das desigualdades sociais, o liberalismo concentra em sua evolução o avanço do pensamento individualista-patrimonialista, voltada ao aumento do patrimônio econômico as custas de uma forma de governo não intervencionista, característica marcante do período liberal.

Ocorre que diante do aumento significativo das discrepâncias sociais, em razão do gozo das garantias liberais se encontrar efetiva em pequenos grupos, o proletariado, irresignado com tais condições, clama pela intervenção estatal a fim de romper com o aumento da invisibilidade direcionada às classes pobres. Em razão disso, emerge o Estado Social, encarregado de intervir no domínio econômico, social e político, afim de aproximar o indivíduo oprimido da convivência com a sociedade e o próprio ente governamental. 
BERNIERI, João Luis; KRAEMER BORTOLOTI, José Carlos. A dificuldade de superação do individualismo no estado democrático de direito no Brasil. Revista Eletrônica Direito e Política, Programa de Pós-Graduação Stricto Sensu em Ciência Jurídica da UNIVALI, Itajaí, v.16, n.2, 20 quadrimestre de 2021. Disponível em: www.univali.br/direitoepolitica - ISSN 1980-7791.

Ademais, aliado ao seu surgimento, visualiza-se o movimento constitucional afim de positivar normas e regular a atuação do Estado frente às dificuldades apresentadas pelo período liberal. Nesse sentido, emergem os direitos sociais, assentados sob normas que exigem, por meio da prestação estatal, tratamento isonômico a todos os indivíduos que se encontram em condição de desigualdade, provendo as classes marginalizadas o acesso a bens básicos para seu reconhecimento como cidadão digno de direitos.

O desenrolar do liberalismo é marcado pelo domínio dos pequenos grupos sociais dotados de grande poder econômico, a classe burguesa, a qual após "acordar" o povo para reinvindicação de seus Direitos, de forma obscura assume o controle do ente estatal, e por meio da implementação de uma política não intervencionista de Estado, dá início, mascaradamente, ao controle do ente governamental. Em detrimento disso, o pensamento individualista-holista ganha força, e os direitos a liberdade inerentes a todos enquanto cidadãos, passam a ser de "poucos".

Com o avanço do desequilíbrio econômico associado as condições desumanas de trabalho, os indivíduos lançados a beira do esquecimento rebelam-se diante da falta de realização das garantias individuais no campo material ${ }^{3}$. Nesse sentido, categórica a lição de Jorge Miranda ao dizer que "os direitos são os mesmos para todos, mas como nem todos se acham em condições para os exercer, é preciso que essas condições sejam criadas ou recriadas"4.

Dessa forma, com base nas problemáticas apresentadas a partir da Revolução Industrial e adotando o slogan utilizado durante a Revolução Francesa5, o proletariado dá início à busca pelo rompimento do pensamento individualista-

\footnotetext{
3 A respeito do tema, Streck e Morais quando elucidam que no Estado Liberal se tem "uma concepção individualista e formal da liberdade, no qual há o direito, e não o poder de ser livre". STRECK, Lenio Luiz; MORAIS, Jose Luis Bolzan de. Ciência Política e Teoria do Estado. 8. Ed. Porto Alegre: Livraria do advogado, 2014, p. 70.

${ }^{4}$ MIRANDA, Jorge. Sobre o princípio da igualdade. In. BORTOLOTI, José Carlos Kraemer. MORAIS, Fausto Santos de (Orgs). A Jurisdição Constitucional e os desafios à concretização dos Direitos Fundamentais: coleção diálogos sobre Estado, Direitos Fundamentais e Jurisdição Constitucional. Rio de Janeiro: Lumen Juris, 2016, p. 10.

5 Nesse sentido Bonavides ao dizer que "a propagação paralela e não menos influente das teses do igualitarismo democrático da Revolução Francesa" para se referir sobre a importância de tal movimento histórico para a emergência do Estado Social. BONAVIDES, Paulo. Ciência Política. 10. ed. São Paulo: Malheiros, 2002, p. 214.
} 
BERNIERI, João Luis; KRAEMER BORTOLOTI, José Carlos. A dificuldade de superação do individualismo no estado democrático de direito no Brasil. Revista Eletrônica Direito e Política, Programa de Pós-Graduação Stricto Sensu em Ciência Jurídica da UNIVALI, Itajaí, v.16, n.2, $2^{\circ}$ quadrimestre de 2021. Disponível em: www.univali.br/direitoepolitica - ISSN 1980-7791.

patrimonialista-burguês, reivindicando a queda de um governo ausente, que diante da forma de atuação em que se encontrava, protegia e alavanca o desenvolvimento dos pequenos grupos detentores do poderio econômico.

Somado aos ideais revolucionários, elementar indicar a influência dos períodos marcados pelos resultados pós-guerras como imprescindível para a superação do liberalismo, uma vez que tais fatos históricos se mostraram capaz de inflamar "uma alteração radical na forma de conceber as relações entre o Estado e a Sociedade" ${ }^{\prime 6}$, preparado para compor o fim de um período gravado pelo crescimento econômico de pequenos grupos.

Basilar a importância dos movimentos constitucionais que, ao lado das grandes guerras mundiais, alcançou por meio da Constituição Mexicana de 1917 e de Weimar em 1919, o ponto máximo para emergência do Estado Social. Tais constituições são recepcionadas como as primeiras a incorporarem em seu texto uma gama de direitos reconhecidos como sociais, uma vez que assim como o Estado Social, buscavam promover a justiça social.

Contudo, o fato de serem recepcionadas como sendo as primeiras a elencar em seu texto normas de cunho social preocupadas em atribuir ao Estado o papel de assistir ao indivíduos, quando estes não possuírem meios para alcançar a realização de suas necessidades por si próprios, não se inaugura a partir do movimento constitucional do século XIX e XX, pois antes mesmo se estabelecer a crise liberal, encontra-se na Grã-Bretanha no século XVII, uma constituição preocupada em organizar uma forma de assistência social? .

A partir de então, a nova forma de atuação de Estado, se mostra completamente às avessas do anterior, pois agora, enlaçado pelo clamor social voltado a incumbir no ente estatal a responsabilidade de um governo atuante, cabendo ao Estado "a palavra de ordem deve determinar e garantir precisamente, sob a

\footnotetext{
${ }^{6}$ NOVAIS, Jorge Reis. Contributo para uma teoria do Estado de Direito: do estado de direito liberal ao estado social e democrático de direito. Editora Almedina: Coimbra, 2006, p.181.

7 NOVAIS, Jorge Reis. Contributo para uma teoria do Estado de Direito: do estado de direito liberal ao estado social e democrático de direito. Editora Almedina: Coimbra, 2006, p.180.
} 
BERNIERI, João Luis; KRAEMER BORTOLOTI, José Carlos. A dificuldade de superação do individualismo no estado democrático de direito no Brasil. Revista Eletrônica Direito e Política, Programa de Pós-Graduação Stricto Sensu em Ciência Jurídica da UNIVALI, Itajaí, v.16, n.2, $2^{\circ}$ quadrimestre de 2021. Disponível em: www.univali.br/direitoepolitica - ISSN 1980-7791.

forma do direito, as linhas e os limites da sua actuação, bem como as esferas de liberdade dos cidadãos ${ }^{8}$.

Sendo assim, as classes lançadas ao esquecimento, passam a reconhecer na figura do Estado, uma forma de limitar o controle econômico da classe burguesa e minimizar as discrepâncias sociais. De todo modo, o empoderamento do ente estatal como interventor nas relações socioeconômicas, é apontado como solução para (re)inserir o indivíduo na vida em sociedade. Canotilho apresenta a necessidade de superação do modelo capitalista-individualista:

Se o capitalismo mercantil e a luta pela emancipação da sociedade burguesa são inseparáveis da consciencialização dos direitos do homem, de feição individualista, a luta das classes trabalhadores $\mathrm{e}$ as teorias socialistas (sobretudo Marx, em A questão Judaica) põem em relevo a unidimensionalização dos direitos do homem egoísta e a necessidade de completar (ou substituir) os tradicionais direitos do cidadão burguês pelos direitos do homem total, o que só seria possível numa nova sociedade, independentemente da adesão aos postulados marxistas, a radicação da ideia da necessidade de garantir o homem no plano econômico, social e cultura, de forma a alcançar um fundamento existencial-material, humanamente digno, passou a fazer parte do patrimônio da humanidade ${ }^{9}$.

Inserido em um novo contexto, ao Estado é conferido o status de superioridade e anterioridade em relação aos indivíduos que Ihe formam, permitindo, à vista disso, uma atuação completamente adversa da qual era incumbido no período liberal, quando no presente contexto, passa a se atribuir de intervenções no âmbito organizacional e de novas diretrizes não só na ordem social, como também na econômica e política.

Não obstante, a aproximação do Estado e sociedade constitui uma forma de governo assentada em um papel intervencionista, capaz de reconhecer as necessidades de seus integrantes e por força de sua atuação prover os meios

\footnotetext{
8 NOVAIS, 2006, p. 180.

9 CANOTILHO, J.J Gomes. Direito Constitucional e Teoria da Constituição. 5 ed. Coimbra: Almedina, 2002, p. 383.
} 
BERNIERI, João Luis; KRAEMER BORTOLOTI, José Carlos. A dificuldade de superação do individualismo no estado democrático de direito no Brasil. Revista Eletrônica Direito e Política, Programa de Pós-Graduação Stricto Sensu em Ciência Jurídica da UNIVALI, Itajaí, v.16, n.2, 20 quadrimestre de 2021. Disponível em: www.univali.br/direitoepolitica - ISSN 1980-7791.

necessários para se alcançar à justiça social ${ }^{10}$, tema objeto das reinvindicações das classes operárias.

A partir de uma atuação intervencionista, o Estado assume aspecto social apto a realização do bem-estar social, quando por meio de sua interferência, o indivíduo visualiza defeso a efetivação de suas garantias de forma a restituir a sua dignidade. Do mesmo modo, tal forma de atuação assumida pelo Estado é denominada por Chevallier como de "Estado Providência"11.

Para Bonavides, o emprego da palavra Social como complemento da ideia de Estado, somente se mostra coerente:

Quando o estado, coagido pela pressão das massas pelas reivindicações que a impaciência do quarto estado faz ao poder político, confere, no Estado Constitucional ou fora deste, os direitos do trabalho, da previdência, da educação, intervêm na economia como distribuidor, dita o salário, manipula a moeda, regula os preços, combate o desemprego, protege os enfermos, dá ao trabalhado e ao burocrata a casa própria, controla as profissões, compra a produção, financia as exportações, concede crédito, institui comissões de abastecimento, provê necessidades individuais, enfrente crises econômicas, coloca na sociedade todas as classes na mais estreita dependência de seu poderio econômico, político e social, em suma, estende sua influência a quase todos os domínios que dantes pertenciam, em grande parte, à área de iniciativa individual, nesse instante o Estado pode, com justiça, receber a denominação de Estado Social ${ }^{12}$.

A emergência do Estado Social é ligada diretamente aos cuidados e medidas adotas em favor dos indivíduos marginalizados ao sistema ${ }^{13}$, tendo em vista à

\footnotetext{
10 Silva ao falar do tema, sugere "à correção do individualismo clássico liberal pela afirmação dos chamados direitos sociais e realização de objetivos de justiça social". SILVA, José Afonso da. Curso de direito constitucional positivo. 16 ed. São Paulo: Malheiros, 1999, p. 119.

${ }^{11}$ CHEVALLIER, Jacques. 0 estado de direito. Belo Horizonte: Fórum, p. 80.

12 BONAVIDES, Paulo. Do Estado liberal ao Estado social. 7 ed. São Paulo: Malheiros Editores, 2001 , p. 186.

13 Novais de forma pontual, ensina que a base do Estado Social encontra-se sob a forma de um Estado que visa, por meio de prestações positivas, formas de diminuir as situações de miséria enfrentadas pelos indivíduos durante a vigência do modelo liberal, como forma de garantir a tais pessoas um meio de subsistirem com um mínimo existencial, por meio da implementação de sistema de serviços ligados a saúde e a assistência social. NOVAIS, Jorge Reis. Contributo para uma teoria do Estado de Direito: do estado de direito liberal ao estado social e democrático de direito. Editora Almedina: Coimbra, 2006, p. 188.
} 
BERNIERI, João Luis; KRAEMER BORTOLOTI, José Carlos. A dificuldade de superação do individualismo no estado democrático de direito no Brasil. Revista Eletrônica Direito e Política, Programa de Pós-Graduação Stricto Sensu em Ciência Jurídica da UNIVALI, Itajaí, v.16, n.2, 20 quadrimestre de 2021. Disponível em: www.univali.br/direitoepolitica - ISSN 1980-7791.

desigualdade material imposta pelo liberalismo. Apropriando-se dos discursos das classes operárias da época, bem como dos ideais Revolucionários Franceses, o Estado insurge em face das desigualdades do período, visando a efetivação das garantias fundamentais positivadas.

Por conseguinte, a procura pelo reconhecimento da dignidade de cada indivíduo por meio da atuação intervencionista do Estado, provoca um equilíbrio em relação à efetividade das garantias liberais, não de modo a exclui-las, de forma alguma, mas de incorporar a sua eficácia à vontade e controle do Estado, com o fito de impossibilitar a extensão dos danos causados por sua livre aplicação.

Ademais, com a ascensão do Estado Social e sua função assistencialista, o Estado passa a intervir no âmbito sócio-político-econômico, razão pela qual tais intervenções são reconhecidas como de "status positivus"14. Contudo, seria equivocado exprimir que a partir de então, como já ressaltado, o Estado passaria a negar as prestações negativas, uma vez que ao se mostrar necessário a intervenção estatal a fim de garantir a efetividade de um direito, se tem de forma quase simultânea, uma manifestação de cunho negativo ${ }^{15}$.

O Estado Social é cimentado sob o prisma de garantir formas de convivência sociais igualitárias, com crença na possibilidade de desenvolvimento do seu

\footnotetext{
${ }^{14}$ Os autores buscam fazer a representação de que as prestações denominadas "negativas", consistiriam na ideia de não intervenção do Estado, como forma de permitir a atuação livre dos indivíduos, permitindo o gozo das garantias individuais, entendidas como naturais. Contudo, a violação de tais direitos, causada pelo pensamento egocêntrico burguês, despertou nas classes menos favorecidas um apelo direcionado a atuação do Estado em benefício de tais indivíduos. Tal atuação prestacional/intervencional do Estado, passa a ser reconhecida como de "status positivus". DIMOULIS, Dimitri. MARTINS, Leonardo. Teoria Geral dos Direitos Fundamentais. 3 ED. Revista atualizada e ampliada. São Paulo: Editora Revista dos Tribunais, 2012, p. 60.

${ }^{15} \mathrm{~A}$ respeito do tema, discorre Sarlet: "Neste sentido, verifica-se, desde logo e na esteira do que já tem sido afirmado há algum tempo entre nós, que também os direitos sociais abrangem tanto direitos prestacionais (positivos) quanto defensivos (negativos), partindo-se aqui do critério da natureza da posição jurídico-subjetiva reconhecida ao titular do direito, bem como da circunstância de que os direitos negativos (notadamente os direitos de não-intervenção na liberdade pessoal e nos bens fundamentais tutelados pela Constituição) apresentam uma dimensão "positiva" (já que sua efetivação reclama uma atuação positiva do Estado e da sociedade) ao passo que os direitos a prestações (positivos) fundamentam também posições subjetivas "negativas", notadamente quando se cuida de sua proteção contra ingerências indevidas por parte dos órgãos estatais, mas também por parte de organizações sociais e de particulares". SARLET, Ingo Wolfgang. Os Direitos Sociais como Direitos Fundamentais: contributo para um balanço aos vinte anos da

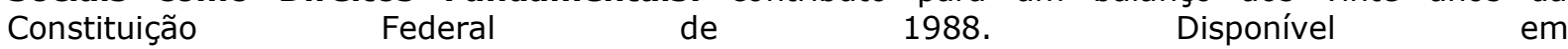
http://www.stf.jus.br/arquivo/cms/processoAudienciaPublicaSaude/anexo/artigo_Ingo_DF_sociais_ PETROPOLIS_final_01_09_08.pdf. Acessado em 10 de outubro de 2020.
} 
BERNIERI, João Luis; KRAEMER BORTOLOTI, José Carlos. A dificuldade de superação do individualismo no estado democrático de direito no Brasil. Revista Eletrônica Direito e Política, Programa de Pós-Graduação Stricto Sensu em Ciência Jurídica da UNIVALI, Itajaí, v.16, n.2, 20 quadrimestre de 2021. Disponível em: www.univali.br/direitoepolitica - ISSN 1980-7791.

povo, por meio de uma atuação fortemente interventora no domínio econômicosocial, limitando o crescimento localizado de capital, de modo a afastar as injustiças oriundas do individualismo-patrimonialista, tendo como resultado um Estado capaz de "prover justiça, ainda que o mundo pereça"16.

Por conseguinte, considera-se que a emergência do Estado Social se deve à necessidade de um governo com feitio capaz de intervir além das esferas econômicas, políticas e sociais, apresentando como propósito de realização a necessidade de um modelo de Estado capaz de reestruturar e aproximar a relação envolvendo o ente estatal, a sociedade e o indivíduo. Ratifica Novais ao dizer que "a nova época exigia era, não apenas um acréscimo das intervenções do Estado, mas uma alteração radical na forma de conceber as suas relações com a sociedade" 17 .

Sob essa perspectiva o homem é levado "a si mesmo, à sua veracidade. Esse homem não existe, porém, no particular, senão no geral; é social, e não individual"18. Ademais, além dos ideais já levantados, o Estado enquanto social, responsabiliza-se, em razão das reinvindicações oriundas das classes trabalhistas, de atribuir a propriedade, enquanto meio de produção, uma função social e não mais de barganha pela força de trabalho.

Sendo assim, a superação aqui trabalhada, apresenta a ideia de uma "estadualização da sociedade e recíproca socialização do Estado"19 como meio indispensável para emergência do Estado de Bem-Estar Social ${ }^{20}$. À vista disso, o

\footnotetext{
16 MALUF, Sahid. Teoria geral do Estado. p. 126 apud SCHLICKMANN, Flávio; KOCH, Rafaela Borgo. A evolução e crise do estado moderno na perspectiva de Lenio Luiz Streck e José Luis Bolzan de Morais. Revista Eletrônica Direito e Política, Programa de Pós-Graduação Stricto Sensu em Ciência Jurídica da UNIVALI, Itajaí, v.8, n.2, $2^{\circ}$ quadrimestre de 2013. Disponível em: http://siaiap32.univali.br/seer/index.php/rdp/article/download/5486/2910. Acessado em 21 de outubro de 2020.

17 NOVAIS, Jorge Reis. Contributo para uma teoria do Estado de Direito: do estado de direito liberal ao estado social e democrático de direito. Editora Almedina: Coimbra, 2006, p. 183.

18 BONAVIDES, Paulo. Do Estado liberal ao Estado social. 7 ed. São Paulo: Malheiros Editores, 2001, p. 171.

19 NOVAIS, 2006, p. 180

20 Nesse sentido, defendendo tal posição Streck e Morais quando dizem que "o desenvolvimento do État Providence ou Estado de Bem-Estar pode ser creditado a duas razões: uma de ordem política, através da luta pelos direitos individuais, pelos direitos políticos e, finalmente, pelos direitos sociais (...)". STRECK, Lenio Luiz. Jurisdição Constitucional e Hermenêutica: Perspectivas e Possibilidades de Concretização dos Direitos Fundamentais-Sociais no Brasil. Revista Novos Estudos Jurídicos - Volume 8 - No 2 - p.257-301, maio/ago. 2003, pg. 266. Disponível em;
} 
BERNIERI, João Luis; KRAEMER BORTOLOTI, José Carlos. A dificuldade de superação do individualismo no estado democrático de direito no Brasil. Revista Eletrônica Direito e Política, Programa de Pós-Graduação Stricto Sensu em Ciência Jurídica da UNIVALI, Itajaí, v.16, n.2, $2^{\circ}$ quadrimestre de 2021. Disponível em: www.univali.br/direitoepolitica - ISSN 1980-7791.

Estado invoca a implementação de políticas e ações públicas como forma de resgatar os indivíduos excluídos da participação social, por força de uma vivência social de garantias liberais apenas em seu aspecto formal.

Com sorte, a ausência de efetividade de tais direitos, expõe a necessidade de intervenção estatal afim de garanti-las.

Com a implementação do modelo Social de Estado, o indivíduo é (re)colocado ao status de origem vivenciado no modelo liberal, uma vez que lhe é estendida a possibilidade de gozar de suas garantias individuais (direitos de liberdade) sob a guarida da máquina estatal.

Outrossim, a exigência de prestações materiais por meio da implementação de políticas públicas voltadas à efetivação das garantias liberais, apresentam-se muito além de seu objetivo central que é o de elevar a condição de cidadão àqueles que antes eram esquecidos, tal realização oferece a todos os indivíduos a capacidade de reconstituir as suas dignidades ${ }^{21}$, quando agora lhe é permitido pertencer a uma comunidade.

Nessa perspectiva, as normas que regulamentavam o Estado, abandonam de fato a seara "formal" e assumem a condição de normas de cunho "material", preocupadas em concretizar todas as atribuições conferidas ao Estado Social. A partir de então, preocupa-se não só com a quantidade de prestações (direitos) estabelecidos no texto constitucional, mas também com a qualidade de sua implementação.

Diante da implementação de políticas públicas voltadas para o desenvolvimento do Estado Social, bem como a necessidade de concretizar a forma pela qual os indivíduos passariam a contar com a assistência e interferência do ente estatal em suas relações, é que as primeiras constituições empregam em seus textos, os

http://siaiap32.univali.br/seer/index.php/nej/article/view/336. Acessado em 29 de setembro de 2020, p. 79.

${ }^{21}$ A respeito do tema da dignidade da pessoa humana, Novais de forma ilustre, pontua que "a dignidade da pessoa humana pôde então, mais do que um direito ou mais do que uma garantia jurídica, ser considerada com um verdadeiro "direito originário a ter direitos". NOVAIS, Jorge Reis.

A Dignidade da Pessoa Humana. Vol. I: Dignidade e Direitos Fundamentais. Coimbra: Editora Almedina, 2015, p. 70. 
BERNIERI, João Luis; KRAEMER BORTOLOTI, José Carlos. A dificuldade de superação do individualismo no estado democrático de direito no Brasil. Revista Eletrônica Direito e Política, Programa de Pós-Graduação Stricto Sensu em Ciência Jurídica da UNIVALI, Itajaí, v.16, n.2, 20 quadrimestre de 2021. Disponível em: www.univali.br/direitoepolitica - ISSN 1980-7791.

chamados direitos sociais e a sua necessária relação com o reconhecimento (Honneth) e as capabilities (Sen).

\section{ESTADO, DIREITOS FUNDAMENTAIS SOCIAIS E RECONHECIMENTO}

A realização dos direitos sociais como fundamentais é ponto vital para proteção e reconhecimento da dignidade dos indivíduos, sob a égide de um Estado Democrático de Direito que figura como engendramento transformador social. Os direitos sociais insurgem em um contexto de vociferação social, marcado pelos muros da invisibilidade, perpetuados em face do excentrismo individualista, que compreende (muitas vezes) na proteção dos direitos sociais o risco para o implemento de direitos exclusivamente focados no indivíduo.

Parece - nesta visão de eterno retorno - que que paira o receio, o medo de que com a efetivação, a proteção dos direitos fundamentais sociais colocará em risco as expectativas mais individuais, principalmente aquelas atreladas às liberdades econômicas individuais, afinal, o Estado em sociabilidade necessita estar atendo às necessidades oriundas dos direitos fundamentais sociais, consequentemente, investindo em políticas públicas de manutenção de tais direitos.

No Brasil, com o advento da Constituição Federal de 1988 e a afirmação de um Estado Democrático de Direito, tenta-se romper com o pensamento individualista-patrimonialista encravado do liberalismo econômico. Com tal intuito, o texto constitucional positivou inúmeros direitos de cunho social, atribuindo ao Estado o dever de realiza-los afim de permitir ao indivíduo o seu reconhecimento como cidadão e a proteção de sua dignidade 22 .

\footnotetext{
22 A respeito da relação da dignidade da pessoa humana com os direitos fundamentais, a primorosa obra de Novais, quando retrata que "[...]assumindo conscientemente a vagueza e diluição de contornos do princípio da dignidade da pessoa humana quando considerado a se, a saída seria encontrada através da identificação do conceito, de forma genérica, com tudo aquilo que se de mais substancial valorizamos e prezamos no Estado de Direito do nosso tempo: direitos fundamentais, em geral, [...] participação democrática e liberdade individual, igualdade, direitos sociais, promoção do igual respeito e consideração devidos a todos os seres humanos, deveres estatais de proteção desses valores e direitos, bem como deveres estatais de prestação dos mínimos materiais necessários a uma vida digna[...]". NOVAIS, Jorge Reis. A Dignidade da
} 
BERNIERI, João Luis; KRAEMER BORTOLOTI, José Carlos. A dificuldade de superação do individualismo no estado democrático de direito no Brasil. Revista Eletrônica Direito e Política, Programa de Pós-Graduação Stricto Sensu em Ciência Jurídica da UNIVALI, Itajaí, v.16, n.2, 20 quadrimestre de 2021. Disponível em: www.univali.br/direitoepolitica - ISSN 1980-7791.

Nesse espectro, ao incluir no Estado de Direito o "princípio Democrático", passase a empregar uma nova concepção do conceito de cidadania, dando enfoque para a afirmação das relações entre os indivíduos, superando (em expectativa), desse modo, a ideia de relação indivíduo e patrimônio ${ }^{23}$, característica do modelo individualista de sociedade.

A partir de então, o Estado (brasileiro) passa a reconhecer os indivíduos como meio justificador de sua existência, conferindo-Ihes uma gama infindável de garantias fundamentais, reconhecendo cada homem como cidadão de direitos.

As promessas constitucionais de 1988 conferem aos indivíduos até então à margem de exercícios de seus direitos, a esperança de uma cidadania plena, articulada e participativa entre o mundo da vida e o sistema representado pelo estado. Como típica promessa, a contemporaneidade mostra que a referida articulação carece de efetividade, bem como a inserção nas promessas constitucionais vai encontrar amparo no Poder Judiciário, tornando-o (perigosamente) um sistema anexo à democracia, afinal, a partir da promessa ainda se acredita na possibilidade de superação do pensamento individualista presente nas sociedades contemporâneas.

[...]é necessário, contudo, ressaltar uma condição: nenhuma legislação no mundo - especialmente dos Direitos Humanos - consegue estabelecer cenários de reconhecimento. O território da legalidade, aqui, não tem força suficiente para se garantir, a longo ou curto prazo, cenários de convívio sadio entre as pessoas [...]Nesse local de sentido observa-se tão somente duas possibilidades: 1) assegurar que não haja quaisquer formas de violência, de omissão ou supressão daquelas condições consideradas indispensável à manutenção da Liberdade, da Igualdade, da Fraternidade e da Justiça; 2) rememorar, constantemente, o que pode ocorrer quando o ser humano se torna reificado[14] ao, de modo seletivo, não se desenvolver mecanismos que coíbam os impulsos excessivamente egoístas ${ }^{24}$

Pessoa Humana. Vol. I: Dignidade e Direitos Fundamentais. Coimbra: Editora Almedina, 2015, p. 68.

${ }^{23}$ STRECK, Lenio Luiz. Verdade e Consenso. Constituição, Hermenêutica e Teorias Discursivas. 4. ed. São Paulo: Saraiva, 2012.

24 AQUINO, Sérgio Ricardo Fernandes de. Essa abominação chamada homem: invisibilidade, reconhecimento e justiça social. Empório do Direito. Disponível em 
BERNIERI, João Luis; KRAEMER BORTOLOTI, José Carlos. A dificuldade de superação do individualismo no estado democrático de direito no Brasil. Revista Eletrônica Direito e Política, Programa de Pós-Graduação Stricto Sensu em Ciência Jurídica da UNIVALI, Itajaí, v.16, n.2, 20 quadrimestre de 2021. Disponível em: www.univali.br/direitoepolitica - ISSN 1980-7791.

Na esteira do que defende Streck, a não passagem do Estado por um Welfare State, prejudica não só a superação do modelo individualista-liberal, mas também sugere o enfraquecimento dos direitos fundamentais e do direito ao "que se relaciona aos valores substantivos constitucionais - como um mecanismo (meramente) redutor de complexidades, impedindo o aparecer do sentido transformador próprio do paradigma do Estado"25.

De fato, a promessa constitucional de 1988 seria de que o modelo liberalindividualista seria desestimulado de nossa cultura sócio-estatal. Contudo, tais medidas não se mostraram suficientes para aproximar a relação indivíduosociedade, mas a impregnação do modelo de Estado de Direito pré-1988 causou um aumento da produção da individualidade.

Tal afirmativa ganha respaldo, na medida em que se vivencia uma judicialização em massa com processos que visam garantir a efetividade dos direitos fundamentais. Não obstante se tratar de direito confiado a todos, o que se busca aqui é apontar que tal fenômeno (da judicialização em massa), em muitas ocasiões, é oriundo de indivíduos que possuem meios próprios para alcançar uma vida digna e ter acesso a bens como medicamentos, escola, mas em razão de projetos pessoais, atribuem ao Estado o dever de tal concessão ${ }^{26}$.

O individualismo contemporâneo experimento pelas sociedades contemporâneas, pouco difere do que lhe fora apresentado durante o período liberal. A obsessão pelo aumento de riquezas pessoais ainda prevalece, o que nos distingue do

http://emporiododireito.com.br/essa-abominacao-chamada/. Acessado em 29 de setembro de 2020.

25 STRECK, Lenio Luiz. Jurisdição Constitucional e Hermenêutica: Perspectivas e Possibilidades de Concretização dos Direitos Fundamentais-Sociais no Brasil. Revista Novos Estudos Jurídicos Volume 8 - No 2 - p.257-301, maio/ago. 2003, pg. 266. Disponível em; http://siaiap32.univali.br/seer/index.php/nej/article/view/336. Acessado em 29 de setembro de 2020.

26 O que se quer discutir aqui, é a necessidade de uma conscientização social, a respeito da exigência judicial das garantias fundamentais, em razão da escassez de recursos públicos. A necessidade de moralização da necessidade do "outro" ser maior do que a do "eu", este é o foco da presente discussão. Em outras palavras "[...]É o reconhecimento que confere viabilidade, eficácia, eficiência e efetividade à Justiça Social[...] propõe limites aos impulsos egoístas do "Eu" [...]". AQUINO, Sérgio Ricardo Fernandes de. Essa abominação chamada homem: invisibilidade, reconhecimento e justiça social. Empório do Direito. Disponível em http://emporiododireito.com.br/essa-abominacao-chamada/. Acessado em 29 de setembro de 2020. 
BERNIERI, João Luis; KRAEMER BORTOLOTI, José Carlos. A dificuldade de superação do individualismo no estado democrático de direito no Brasil. Revista Eletrônica Direito e Política, Programa de Pós-Graduação Stricto Sensu em Ciência Jurídica da UNIVALI, Itajaí, v.16, n.2, 20 quadrimestre de 2021. Disponível em: www.univali.br/direitoepolitica - ISSN 1980-7791.

período liberal, é que agora, mediante a positivação das garantias fundamentais sociais, todos os cidadãos atribuem ao Estado o dever de efetivar tais direitos.

Não obstante, a projeção do desenvolvimento econômico individual é uma das barreiras erguidas frente a dificuldade de reconhecimento do "outro" e a presença do pensamento individualista-liberal.

Nesse sentido, visualiza-se repetida e incansavelmente cada vez mais cidadãos preocupados em imputar ao Estado a responsabilidade pelo fornecimento de bens que, por meios próprios poderiam ser adquiridos, adotando como premissa de tal responsabilização, que essa é sua função.

Tal pensamento denúncia, gritantemente, a falta de sensibilidade presente em nossa sociedade, de reconhecer o "outro" e suas necessidades como mais imediatas do que a do "eu", corroborando para a dificuldade de reconhecimento e afirmação da alteridade 27 , bem como confirmando que o "Welfare State não passou de um simulacro"28 no Brasil.

O cenário pelo qual passamos em relação aos direitos fundamentais, é caótico, pois, as dificuldades enfrentadas pelo Estado em efetivar as garantias fundamentais, bem como a escassez de recursos públicos, alertam para "uma crise de direitos fundamentais" 29 . Em virtude disso, a promoção da justiça social, a que se propõe o texto constitucional, somente se mostrará possível, no

\footnotetext{
27"[...]a sensibilidade é um vetor, uma ponte e um caminho de trânsito, de conflitos, de reconhecimento entre o "Eu" e o "Tu". É esta transição denominada de Alteridade, matriz ética de nossas responsabilidades comuns[...]". AQUINO, Sergio Ricardo Fernandes de; MAGRO, Diogo Dal. Direitos Humanos, sensibilidade e alteridade: um desafio do século XXI. Empório do Direito. Disponível em http://emporiododireito.com.br/direitos-humanos-sensibilidade-e-alteridade-umdesafio-do-seculo-xxi-por-sergio-ricardo-fernandes-de-aquino-e-diogo-dal-magro/. Acessado em 29 de setembro de 2020.

28 STRECK, Lenio Luiz. Jurisdição Constitucional e Hermenêutica: Perspectivas e Possibilidades de Concretização dos Direitos Fundamentais-Sociais no Brasil. Revista Novos Estudos Jurídicos Volume 8 - No 2 - p.257-301, maio/ago. 2003, pg. 266. Disponível em; http://siaiap32.univali.br/seer/index.php/nej/article/view/336. Acessado em 29 de setembro de 2020, p. 278.

29 Para o autor, a crise dos direitos fundamentais se deve em razão da colisão negativa que a globalização tanto econômica, quanto social, acarreta em países em desenvolvimento, como é o caso do Brasil. As consequências de tais impactos, só podem resultar em uma diminuição da capacidade prestacional da máquina estatal, que por consequência contaminam, diretamente, a efetivação das garantias fundamentais, como o direito à igualdade. SARLET, Ingo Wolfgang. Os direitos fundamentais na constituição de 1988. Revista Diálogo Jurídico. Salvador, v.1, n.1, pg. 1-46, abril, 2001, pp. 1-46.
} 
BERNIERI, João Luis; KRAEMER BORTOLOTI, José Carlos. A dificuldade de superação do individualismo no estado democrático de direito no Brasil. Revista Eletrônica Direito e Política, Programa de Pós-Graduação Stricto Sensu em Ciência Jurídica da UNIVALI, Itajaí, v.16, n.2, 20 quadrimestre de 2021. Disponível em: www.univali.br/direitoepolitica - ISSN 1980-7791.

contexto brasileiro, se os cidadãos passarem a reconhecer a existência do "outro" como cidadão.

Ademais, o dicionário define cidadão como 1-habitante da cidade e 2- indivíduo que, como membro de um Estado, usufrui de direitos civis e políticos por este garantidos e desempenha os deveres que, nessa condição, Ihe são atribuídos ${ }^{30}$. Pois bem, o princípio da dignidade da pessoa humana em conjunto com as garantias fundamentais, visam reconhecer o indivíduo afetado pela invisibilidade como cidadão.

Para ser reconhecido como cidadão, basta que o indivíduo seja membro de um Estado, e a ele seja oportunizado gozar de todos os direitos inerentes a sua pessoa. Ocorre, que em tempos aonde o "outro" não é preocupação do "eu", logo "a imagem, a presença, o estar-no-mundo, não é suficiente para desfazer a invisibilidade social" ${ }^{31}$ e permitir ao indivíduo sua identificação como cidadão.

O reconhecimento, é peça fundamental para que se retire o véu da invisibilidade dos indivíduos que se encontram espalhados em nosso território, mas que não são recebidos como cidadão. Afim de instigar a uma reflexão mais profundo acerca do tema, Levi:

Vocês que vivem seguros em suas cálidas casas, vocês que, voltando à noite, encontram comida quente e rostos amigos, pensem bem se isto é um homem que trabalha no meio do barro, que não conhece paz, que luta por um pedaço de pão, que morre por um sim ou por um não. Pensem bem se isto é uma mulher, sem cabelos e sem nome, sem mais força para lembrar, vazios os olhos, frio o ventre, como um sapo no inverno. Pensem que isto aconteceu: eu lhes mando estas palavras. Gravem-na em seus corações, estando em casa, andando na rua, ao deitar, ao levantar; repitam-nas a seus filhos. Ou, senão, desmorone-se a sua casa, a doença os torne inválidos, os seus filhos virem o rosto para não vê$\operatorname{los}^{32}$

\footnotetext{
30 Conceito retirado em https://www.dicio.com.br/cidadao/. Acessado em 04 de outubro de 2020.

31 AQUINO, Sérgio Ricardo Fernandes de (Contra o) eclipse da esperança: escritos sobre a(s) assimetria (s) entre direito e Dados eletrônicos. - Itajaí: UNIVALI, 2017.

32 LEVI, Primo. Se questo é un uomo? Texto traduzido por RE, Luigi del. Rio de Janeiro: editora Rocco, pg. 9. Disponível em https://joaocamillopenna.files.wordpress.com/2015/03/levi-primoc3a9-isto-um-homem-1988.pdf. Acessado em 04 de outubro de 2020.
} 
BERNIERI, João Luis; KRAEMER BORTOLOTI, José Carlos. A dificuldade de superação do individualismo no estado democrático de direito no Brasil. Revista Eletrônica Direito e Política, Programa de Pós-Graduação Stricto Sensu em Ciência Jurídica da UNIVALI, Itajaí, v.16, n.2, 20 quadrimestre de 2021. Disponível em: www.univali.br/direitoepolitica - ISSN 1980-7791.

Nesse contexto, apresentam-se todos os inúmeros moradores de rua, dos conjuntos habitacionais precários, todos aqueles a que se atribuí os mais despretensiosos objetivos de vida.

Em uma rápida reflexão, Dias propõe uma reflexão a respeito do que é uma boa vida. Descreve tal possibilidade, com reservas, quando se realizada a comparação com a de outros indivíduos, e ainda abre espaço para mais um questionamento, qual seja, "se a minha vida requer o sofrimento dos outros, a negação de suas próprias vidas, isso pode ser chamado de vida boa?" De fato, as respostas para tais indagações ganham força para um debate quase infindável, e como não poderia ser diferente, por se tratar de um texto reflexivo, o autor conclui indagando "como é possível uma vida boa em uma vida ruim?"33

A comparação que se sustenta sob o aspecto de comparativo da vida do eu em face de outros indivíduos, projeta dois tipos de reflexão, pois quando comparada com a vida de seres que vivem à beira da invisibilidade, reconhece-se o pertencimento a classe de privilegiados, enquanto relacionada a pequena parcela de indivíduos que detém grande poderio econômico, nos projetamos como pertencentes a classe excluída, marginalizada ${ }^{34}$.

A distorção de tais direitos fica clara quando Cittadino elucida que:

Os direitos civis e políticos são, portanto, a todos destinados, enquanto os direitos sócio-econômicos estão associados ao processo de inclusão social daqueles que, na ausência de tais direitos, encontrariam grande dificuldade não apenas de conduzir com dignidade suas vidas, como também em atuar no cenário público. ${ }^{35}$

\footnotetext{
33 DIAS, Renato Duro. Em busca de justiça social ou o que é uma boa vida? Tradução da obra Qu'est-ce qu'une vie bonne?" de Judith Butler, 2014. Disponível em http://emporiododireito.com.br/em-busca-de-justica-social-ou-o-que-e-uma-boa-vida/. Acessado em 04 de outubro de 2020.

34 "Nesse sentido, é isso que a estética nos faz perceber: a diferença do outro, ainda que no outro queiramos encontrar apenas a igualdade, a igualdade que nos faz, por exemplo, comuns por sermos humanos." BITTAR, Eduardo Carlos Bianca, Democracia, Justiça e Direitos Humanos: estudos de teoria crítica e filosofia do direito. São Paulo: Saraiva, 2013, p. 138.

35 CITTADINO, Gisele. "Invisibilidade", Estado de Direito e Política de Reconhecimento. XXVII Encontro Anual da ANPOCSGT 19: República e Cidadania: Teorias e Debates Contemporâneos Coordenadores: José Eisenberg e Cícero Araújo. 2003. Disponível em http://www.anpocs.org/portal/index.php?option=com_docman\&task=doc_view\&gid=4275\&Itemid $=316$. Acessado em 12 de outubro de 2020 .
} 
BERNIERI, João Luis; KRAEMER BORTOLOTI, José Carlos. A dificuldade de superação do individualismo no estado democrático de direito no Brasil. Revista Eletrônica Direito e Política, Programa de Pós-Graduação Stricto Sensu em Ciência Jurídica da UNIVALI, Itajaí, v.16, n.2, 20 quadrimestre de 2021. Disponível em: www.univali.br/direitoepolitica - ISSN 1980-7791.

Nesse sentido, ao adotar o modelo neoconstitucional como forma de reação aos regimes autoritários que "marcados, singularmente, pelo não reconhecimento do outro, da alteridade, a ausência da solidariedade"36, é que as garantias fundamentais encontrariam razão de existir na Constituição brasileira.

Tudo isso, nos faz pensar se o homem, é realmente um ser social, pois na medida em que se coloca para vida em sociedade, mais se identifica aspectos de que o homem em nada é um ser voltado para si, centrado em si. Resta a constatação de que "conduzir a vida, de forma autônoma, significa mitigar as fragilidades comuns, as desigualdades a partir de relações pautadas pelo reconhecimento" ${ }^{\prime 37}$.

Ademais, as diferenças e as pluralidades são características originárias da democracia, reconhecendo-as, estaremos diante da possibilidade de formação de uma sociedade justa. A sensibilidade de conhece-las, valida a dignidade de seus semelhantes e, desse modo, se torna possível visualizar os demais indivíduos como (cidadãos) participantes da vida em sociedade, dotado de direitos e garantias.

A descentralização do ser egocêntrico, é papel fundamental para libertá-lo do amor exagerado de si próprio e assim tornar legítimo o valor do "outro", bem como sua autonomia. Nas palavras de Honneth, "reconociendo a alguien, en el sentido de concederle una autoridad moral sobre mí, estoy motivado al mismo tiempo a tratarlo en el futuro de acuerdo con su valor"138.

Desse modo, admitindo a alteridade enquanto meio para uma (con)vivência com o "outro", a ideia de que as garantias fundamentais no Estado brasileiro são normas vazias, mudam de perspectiva. Pois, como bem destaca Warat, "definitivamente a questão dos direitos humanos é uma questão de alteridade.

\footnotetext{
36 ROSSI, Amélia Sampaio. Neoconstitucionalismo e direitos fundamentais. Constitucionalismo contemporâneo $\mathrm{x}$ positivismo jurídico. A realização dos direitos fundamentais sob a $\quad$ perspectiva neoconstitucionalista. Disponível em http://www.publicadireito.com.br/conpedi/manaus/arquivos/anais/salvador/amelia_do_carmo_sam paio_rossi.pdfAcessado em 04 de outubro de 2020.

37 HONNETH, Axel; ANDERSON, Joel. Autonomia, Vulnerabilidade, Reconhecimento e Justiça. Cadernos de Filosofia Alemã: Crítica e Modernidade. https://www.dicio.com.br/cidadao/. Acessado em 04 de outubro de 2020, p. 87.

38 HONNETH, Axel. La sociedad del desprecio. Madrid: Editorial Trotta, 2011, p. 176.
} 
BERNIERI, João Luis; KRAEMER BORTOLOTI, José Carlos. A dificuldade de superação do individualismo no estado democrático de direito no Brasil. Revista Eletrônica Direito e Política, Programa de Pós-Graduação Stricto Sensu em Ciência Jurídica da UNIVALI, Itajaí, v.16, n.2, 20 quadrimestre de 2021. Disponível em: www.univali.br/direitoepolitica - ISSN 1980-7791.

Não podemos falar de Direitos humanos ignorando o componente da alteridade que o constitui em estrutura"39.

Portanto, o constituinte ao atribuir como sendo de todos o direito a exigir do Estado as garantias fundamentais, influenciado pelo movimento socialista dos países europeus, os quais experimentaram, de fato, o Welfare State, insere tais prestações, visando atender aos indivíduos que se encontram a margem do esquecimento ${ }^{40}$. Contudo, não superada a ideia liberal-individual de que é dever do Estado garantir a todos, de uma forma geral, a efetivação dos direitos fundamentais, continuar-se-á remando a favor da produção da invisibilidade social.

Aqui fundamental a contribuição de Amartya Sen em sua obra A ideia de justiça, quando aborda temática sobre a Abordagem das capacidades. No referido capítulo Sen indica que as a "abordagem das capacidades se concentra na vida humana e não apenas em alguns objetivos separados de convivência, como rendas ou mercadorias que uma pessoa pode possui"41, tais inserções estão vinculadas exclusivamente na ideia de liberdade e econômica "como critério principal do sucesso humano"42.

A preocupação de Sen vai focar "desde a concentração nos meios de vida até as oportunidades reais de vida"43. Quer dizer, a opção de escolha em desenvolver determinado tipo de vida deve ser a condição real à disposição do ser humano. 0 volume considerável de marginalizados dos direitos elementares para sobrevivência, estão afastados das oportunidades reais de vida, não chegam sequer a figurar em um plano hipotético de liberdade econômica, mas permanecem fadados à sua condição de ausência de escolha.

39 WARAT, Luis Alberto. A rua grita Dionísio! direitos humanos de alteridade, surrealismo e cartografia. Tradução de Vívian Alves de Assis, Julio Cesar Marcellino Júnior e Alexandre Morais da Rosa. Rio de Janeiro: Lúmen Juris, 2010, p. 116.

40 Nas palavras de Dias "[...]é preciso compreender que uma política de igualdade não necessita ser uma política de identidade única, posto ser fundamental o reconhecimento das diferenças. Negar o direito à diferença é forjar um falso direito à igualdade. Portanto, para além de simplesmente reivindicarmos 'novas' políticas de identidade, necessitamos atrelá-las a políticas de igualdade consubstanciada no reconhecimento das diferenças". DIAS, 2014.

41 SEN, Amartya. A ideia de justiça. Tradução Denise Bottman e Ricardo Doninelli Mendes. São

Paulo: Companhia das Letras, 2006, p. 198.

42 SEN, 2006, p. 198.

43 SEN, 2006, p. 198. 
BERNIERI, João Luis; KRAEMER BORTOLOTI, José Carlos. A dificuldade de superação do individualismo no estado democrático de direito no Brasil. Revista Eletrônica Direito e Política, Programa de Pós-Graduação Stricto Sensu em Ciência Jurídica da UNIVALI, Itajaí, v.16, n.2, ${ }^{\circ}$ quadrimestre de 2021. Disponível em: www.univali.br/direitoepolitica - ISSN 1980-7791.

É preciso reconhecer todos os indivíduos, como cidadãos, superar a ideia de que o "outro" é um inimigo constante para realização das vontades particulares. A neurose capitalista-patrimonialista, ainda presente na sociedade brasileira, inflamada pela valorização do patrimônio e da liberdade econômica, leva a continuidade de uma estrutura de cidadania sem condições de oportunidades reais de vida, no sentido dado por Sen.

\section{CONSIDERAÇÕES FINAIS}

Diante do estudo realizado neste ensaio cumpre tecer algumas considerações finais. A trajetória dos direitos fundamentais ao longo da história se desenvolve conexa a fatos trágicos. Sob a égide de atribuir aos indivíduos a condição de cidadão portador de direitos básicos e naturais ao homem, bem como garantir a proteção de sua dignidade é que as garantias fundamentais são lançadas no texto constitucional.

Dos primeiros movimentos sociais do Estado de direito se vislumbram uma série de garantias individuais, afim de promover a livre relação entre os homens sem qualquer interferência autoritária do Estado. Contudo, o desenvolvimento econômico sustentado sob a ótica do capitalismo, acabou por frear o gozo das liberdades individuais, ao passo que excessivamente centrado no cidadão com condições de exercício das liberdades a partir do fomento econômico.

A partir de então, os indivíduos que não concentram grandes posses, em consequência não detém poder econômico, passam a ter um caráter meramente simbólico representativo na democracia brasileira, lançados a beira da invisibilidade, e com baixíssimas oportunidades reais de vida, conforme argumenta Amartya Sen em sua Ideia de Justiça.

A (re) emergência do Estado Social, agora atrelado aos parâmetros do Estado Democrático de Direito, preocupa-se em efetivar as garantias fundamentais de liberdade e assegurar ao indivíduo o acesso a bens que por suas forças não alcançaria. Nesse sentido, figura sob a tônica de ser o responsável pela 
BERNIERI, João Luis; KRAEMER BORTOLOTI, José Carlos. A dificuldade de superação do individualismo no estado democrático de direito no Brasil. Revista Eletrônica Direito e Política, Programa de Pós-Graduação Stricto Sensu em Ciência Jurídica da UNIVALI, Itajaí, v.16, n.2, 20 quadrimestre de 2021. Disponível em: www.univali.br/direitoepolitica - ISSN 1980-7791.

superação do pensamento individualista ao (re)estabelecer a dignidade de cada indivíduo, e atribuir aos indivíduos a possibilidade de serem reconhecidos como cidadãos.

As primeiras constituições presentes no Estado Social (de direito), posicionam em seus textos normas regulamentadoras da atuação estatal, bem como inauguram a nova dimensão dos direitos fundamentais, os sociais. Positivados para serem direitos de promoção e proteção, direcionam-se no sentido de promover a igualdade de condições para os mais carentes, fornecendo acesso a saúde, educação, trabalho digno, dentre outros direitos. Busca-se (re)inserir o indivíduo marginalizado à vida em sociedade, reconhecendo desse modo sua dignidade, de maneira a harmonizar a relação entre Estado e cidadãos.

O presente texto é uma provocação ao intérprete do direito para uma observação da problemática da não superação do pensamento individualista-patrimonialista liberal na sociedade brasileira contemporânea, a partir de uma análise a respeito da efetivação e reconhecimento dos direitos sociais (como) fundamentais. Possibilita-se apontar que a falsa experiência brasileira de passagem por um Estado Social é tida como consequência para formação de cidadãos egocêntricos, incapazes de identificar que a atribuição do Estado é de prestar apoio aos que vivem à beira do esquecimento.

Aliada ao simulacro de Estado Social no Brasil, a falta de alteridade dos cidadãos brasileiros ${ }^{44}$, mantém acesa a centelha do individualismo nos dias de hoje, na medida em que os cidadãos reconhecem os que estão a sua volta como ameaças para efetivação de seus direitos. Necessita-se na realidade brasileira uma moralização da sociedade em prol do emprego dos direitos fundamentais aos indivíduos que não possuem meios para gozar de uma vida digna.

\footnotetext{
44"[...]A "invisibilidade" talvez seja a forma mais sutil, silenciosa e imperceptível de apartheid social, uma forma aprimorada de percepção seletiva mediante a qual as pessoas simplesmente não veem aqueles cujo "tipo" já foi antecipadamente (preconceituosamente) excluído do seu campo de visão. E é interessante notar que esse distanciamento, essa "cegueira" esteja tão arraigada na sociedade, que acontece mecanicamente, inconscientemente. E isso aumenta ainda mais a eficácia dessa forma de exclusão!". Sobre a rejeição aos pobres. NETO, Agostinho Ramalho Marques. Empório do Direito, 06 de dezembro de 2015. Disponível em http://emporiododireito.com.br/sobre-a-rejeicao-aos-pobres/. Acessado em 07 de outubro de 2020.
} 
BERNIERI, João Luis; KRAEMER BORTOLOTI, José Carlos. A dificuldade de superação do individualismo no estado democrático de direito no Brasil. Revista Eletrônica Direito e Política, Programa de Pós-Graduação Stricto Sensu em Ciência Jurídica da UNIVALI, Itajaí, v.16, n.2, $2^{\circ}$ quadrimestre de 2021. Disponível em: www.univali.br/direitoepolitica - ISSN 1980-7791.

A partir do reconhecimento do outro (Honneth) e a garantia de oportunidades reais de vida (Sen), é que se conseguirá superar o modelo individualistapatrimonialista, que ainda se faz presente na sociedade brasileira, enquanto não se conseguir enxergar no "outro" como se estivesse vendo a mim mesmo, continuar-se-á produzir "cidadãos" esquecidos.

\section{REFERÊNCIAS DAS FONTES CITADAS}

AQUINO, Sérgio Ricardo Fernandes de (Contra o) eclipse da esperança: escritos sobre $a(s)$ assimetria (s) entre direito e Dados eletrônicos. - Itajaí: UNIVALI, 2017.

AQUINO, Sérgio Ricardo Fernandes de. Essa abominação chamada homem: invisibilidade, reconhecimento e justiça social. Empório do Direito. Disponível em http://emporiododireito.com.br/essa-abominacao-chamada/. Acessado em 29 de setembro de 2020.

AQUINO, Sergio Ricardo Fernandes de; MAGRO, Diogo Dal. Direitos Humanos, sensibilidade e alteridade: um desafio do século XXI. Empório do Direito. Disponível em http://emporiododireito.com.br/direitos-humanos-sensibilidade-ealteridade-um-desafio-do-seculo-xxi-por-sergio-ricardo-fernandes-de-aquino-ediogo-dal-magro/. Acessado em 29 de setembro de 2020.

BITTAR, Eduardo Carlos Bianca. Democracia, Justiça e Direitos Humanos: estudos de teoria crítica e filosofia do direito. São Paulo: Saraiva, 2013.

BONAVIDES, Paulo. Ciência Política. 10. ed. São Paulo: Malheiros, 2002.

BONAVIDES, Paulo. Do Estado liberal ao Estado social. 7 ed. São Paulo: Malheiros Editores, 2001.

CANOTILHO, J.J Gomes. Direito Constitucional e Teoria da Constituição. 5 ed. Coimbra: Almedina, 2002.

CITTADINO, Gisele. "Invisibilidade", Estado de Direito e Política de Reconhecimento. XXVII Encontro Anual da ANPOCSGT 19: República e Cidadania: Teorias e Debates Contemporâneos Coordenadores: José Eisenberg e Cícero Araújo. 2003. Disponível em http://www.anpocs.org/portal/index.php?option=com_docman\&task=doc_view\& gid=4275\&Itemid=316. Acessado em 12 de outubro de 2020.

CHEVALLIER, Jacques. O estado de direito. Belo Horizonte: Fórum, 2013. 
BERNIERI, João Luis; KRAEMER BORTOLOTI, José Carlos. A dificuldade de superação do individualismo no estado democrático de direito no Brasil. Revista Eletrônica Direito e Política, Programa de Pós-Graduação Stricto Sensu em Ciência Jurídica da UNIVALI, Itajaí, v.16, n.2, $2^{\circ}$ quadrimestre de 2021. Disponível em: www.univali.br/direitoepolitica - ISSN 1980-7791.

DIMOULIS, Dimitri. MARTINS, Leonardo. Teoria Geral dos Direitos Fundamentais. 3 ED. Revista atualizada e ampliada. São Paulo: Editora Revista dos Tribunais, 2012.

DIAS, Renato Duro. Em busca de justiça social ou o que é uma boa vida? Tradução da obra Qu'est-ce qu'une vie bonne ?" de Judith Butler, 2014. Disponível em http://emporiododireito.com.br/em-busca-de-justica-social-ou-oque-e-uma-boa-vida/. Acessado em 04 de outubro de 2020.

HONNETH, Axel; ANDERSON, Joel. Autonomia, Vulnerabilidade, Reconhecimento e Justiça. Cadernos de Filosofia Alemã: Crítica e Modernidade. https://www.dicio.com.br/cidadao/. Acessado em 04 de outubro de 2020.

HONNETH, Axel. La sociedad del desprecio. Madrid: Editorial Trotta, 2011.

LEVI, Primo. Se questo é un uomo? Rio de Janeiro: editora Rocco. Disponível em https://joaocamillopenna.files.wordpress.com/2015/03/levi-primo-c3a9-istoum-homem-1988.pdf. Acessado em 04 de outubro de 2020.

MIRANDA, Jorge. Sobre o princípio da igualdade. In. BORTOLOTI, José Carlos Kraemer. MORAIS, Fausto Santos de (Orgs). A Jurisdição Constitucional e os desafios à concretização dos Direitos Fundamentais: coleção diálogos sobre Estado, Direitos Fundamentais e Jurisdição Constitucional. Rio de Janeiro: Lumen Juris, 2016.

SCHLICKMANN, Flávio; KOCH, Rafaela Borgo. A evolução e crise do estado moderno na perspectiva de Lenio Luiz Streck e José Luis Bolzan de Morais.

Revista Eletrônica Direito e Política, Programa de Pós-Graduação Stricto Sensu em Ciência Jurídica da UNIVALI, Itajaí, v.8, n.2, $2^{\circ}$ quadrimestre de 2013. Disponível em:

http://siaiap32.univali.br/seer/index.php/rdp/article/download/5486/2910.

Acessado em 21 de outubro de 2020.

NOVAIS, Jorge Reis. Contributo para uma teoria do Estado de Direito: do estado de direito liberal ao estado social e democrático de direito. Editora Almedina: Coimbra, 2006.

NOVAIS, Jorge Reis. A Dignidade da Pessoa Humana. Vol. I: Dignidade e Direitos Fundamentais. Coimbra: Editora Almedina, 2015.

ROSSI, Amélia Sampaio. Neoconstitucionalismo e direitos fundamentais. Constitucionalismo contemporâneo $x$ positivismo jurídico. A realização dos direitos fundamentais sob a perspectiva neoconstitucionalista. Disponível em http://www.publicadireito.com.br/conpedi/manaus/arquivos/anais/salvador/amel ia_do_carmo_sampaio_rossi.pdf. Acessado em 04 de outubro de 2020.

SARLET, Ingo Wolfgang. Os Direitos Sociais como Direitos Fundamentais: contributo para um balanço aos vinte anos da Constituição Federal de 1988. Disponível em http://www.stf.jus.br/arquivo/cms/processoAudienciaPublicaSaude/anexo/artigo 
BERNIERI, João Luis; KRAEMER BORTOLOTI, José Carlos. A dificuldade de superação do individualismo no estado democrático de direito no Brasil. Revista Eletrônica Direito e Política, Programa de Pós-Graduação Stricto Sensu em Ciência Jurídica da UNIVALI, Itajaí, v.16, n.2, $2^{\circ}$ quadrimestre de 2021. Disponível em: www.univali.br/direitoepolitica - ISSN 1980-7791.

Ingo_DF_sociais_PETROPOLIS_final_01_09_08.pdf. Acessado em 10 de outubro de 2020.

SARLET, Ingo Wolfgang. Os direitos fundamentais na constituição de 1988. Revista Diálogo Jurídico. Salvador, v.1, n.1, pg. 1-46, abril, 2001.

SEN, Amartya. A ideia de justiça. Tradução Denise Bottman e Ricardo Doninelli Mendes. São Paulo: Companhia das Letras, 2006.

SILVA, José Afonso da. Curso de direito constitucional positivo. 16 ed. São Paulo: Malheiros, 1999.

STAFFEN, Márcio Ricardo. Estado, constituição e juizados especiais federais. Rio de Janeiro: Lumen Juris, 2015.

STAFFEN, Márcio Ricardo. Reflexões sobre o Estado constitucional em Hans Kelsen. Revista Thesis Juris, n. 1, v. 1, São Paulo, dez. 2012.

STRECK, Lenio Luiz; MORAIS, Jose Luis Bolzan de. Ciência Política e Teoria do Estado. 8. Ed. Porto Alegre: Livraria do advogado, 2014.

STRECK, Lenio Luiz. Jurisdição Constitucional e Hermenêutica: Perspectivas e Possibilidades de Concretização dos Direitos Fundamentais-Sociais no Brasil. Revista Novos Estudos Jurídicos - Volume 8 - No 2 - p.257-301, maio/ago. 2003, pg. 266. Disponível em; http://siaiap32.univali.br/seer/index.php/nej/article/view/336. Acessado em 29 de setembro de 2020.

STRECK, Lenio Luiz. Verdade e Consenso. Constituição, Hermenêutica e Teorias Discursivas. 4. ed. São Paulo: Saraiva, 2012.

WARAT, Luis Alberto. A rua grita Dionísio! Direitos humanos de alteridade, surrealismo e cartografia. Tradução de Vívian Alves de Assis, Julio Cesar Marcellino Júnior e Alexandre Morais da Rosa. Rio de Janeiro: Lúmen Juris, 2010.

RECEBIDO EM: JAN/2021

APROVADO EM: MAR/2021 